\section{MOSAICO DE ALEXANDRE NA CASA DO FAUNO EM POMPEIA: ONTEM E HOJE ${ }^{1}$}

\author{
Renata Senna Garraffoni* \\ José Geraldo Costa Grillo**
}

Recebido em: 09/03/2020

Aprovado em: 31/03/2020

RESUMO: O objetivo central desse artigo é realizar um estudo de caso sobre o mosaico de Alexandre, localizado na Casa do Fauno em Pompeia, para pensar as formas de recepção de Alexandre no passado e presente. Para tanto iniciamos problematizando aspectos da escavação da cidade de Pompeia para, na sequência, discutirmos a Casa do Fauno e descrever os detalhes do Mosaico. Na sequência analisamos os primeiros estudos do Mosaico e as formas de entender a arte no século XIX para, por fim, pensar algumas das abordagens mais recentes, discutindo os desdobramentos das novas leituras sobre os encontros entre Oriente e Ocidente. Almejamos, portanto, trazer à tona as complexas relações entre passado e presente, entre arte e materialidade, recepção e diversidade étnica.

PALAVRAS-CHAVE: Mosaico de Alexandre; Casa do Fauno; Arqueologia contextual; recepção.

\section{ALEXANDER MOSAIC AT THE HOUSE OF THE FAUN IN POMPEII: YESTERDAY AND TODAY}

* Professora Associada, Departamento de História, Universidade Federal do Paraná.

resenna93@gmail.com

(1)

\section{** Professor Associado,} Departamento de

História da Arte, Universidade Federal de São Paulo. jgcgrillo@yahoo.com.br

\footnotetext{
ABSTRACT: The aim of this paper is to take the Alexander mosaic, located at the House of the Faun in Pompeii, as a case study to discuss Alexander reception in the past and present. To do so, first we discuss some issues related to Pompeii's excavation; second, we shall focus at the

${ }^{1}$ Agradecemos a todos e todas que participaram do minicurso ministrado na ocasião do Simpósio "Alexandre...Alexandre! Alexandre: os aspectos do guerreiro, do sábio e do soberano na narrativa", realizado na Universidade Federal do Paraná em dezembro de 2018. As perguntas e os debates foram imprescindíveis para aprofundarmos alguns dos pontos explorados neste artigo. Destacamos, no entanto, que a responsabilidade das ideias aqui publicadas recai apenas sobre a autora e o autor.
} 
House of the Faun and describe the details of the Mosaic. Then we shall present the first studies of the Mosaic and the ways of understanding the art in the 19th century to, finally, discuss some of the most recent approaches, pointing out the recent debates between East and West. We aim, therefore, to bring to light the complex relations between past and present, art and materiality, reception and ethnic diversity.

KEYWORDS: Alexander Mosaic; House of the Faun; Post-processual Archaeology; Reception studies.

\section{INTRODUÇÃO}

Vernant defendeu, em várias ocasiões, que textos ou imagens não devem ser lidos como imediatos ou transparentes. Para compreendê-los melhor em seus contextos é preciso um esforço para penetrar nos múltiplos códigos culturais que os gregos conferiam a suas figuras, tornando o trabalho dos intelectuais mais complexo que a mera equiparação texto/imagem (Vernant, 1984, p. 4). Retomamos essas considerações de Vernant, pois elas indicam os desafios que nos atingem ao tratar do objeto de estudo deste artigo, o Mosaico de Alexandre, encontrado na Casa do Fauno, em Pompeia. Para além de ser uma imagem bastante conhecida e estudada, o mosaico nos insere em debates sobre a figura de Alexandre entre os gregos, bem como sobre sua recepção no contexto romano e posterior. Assim, as considerações teóricas de Vernant nos alertam para o fato de que, muito antes da ascensão de Roma, o líder macedônico desempenhou um papel político e cultural sem precedentes no mundo antigo: seus retratos e suas ideias circularam intensamente, suas virtudes e vícios foram contados e recontados nos mais diferentes suportes, encarnando o que deveria ser um líder guerreiro e criando códigos múltiplos de possibilidades de leituras. Mais recentemente, Pollini (2012, p. 162) afirmou que Alexandre se tornou mais que um construtor de impérios, seus feitos serviram de base de comparação a tantos outros líderes ao longo da História, transformando-o numa figura multifacetada e complexa, inserida em processos de recepção bastante particulares em cada contexto em que foi evocado.

Há, portanto, uma miríade de formas de se aproximar de Alexandre que a tradição nos legou, seja pela arte, seja pela literatura, seja pelos estudos arqueológicos e históricos a partir do século XIX. São esses últimos que nos interessam nessa ocasião e, mesmo assim, há uma ampla literatura sobre o tema. Tronson (2004), por exemplo, chama a atenção para ao menos cinco possibilidades de se estudar, na academia, o jovem macedônico: 1) as fontes materiais e escritas que moldam as abordagens sobre sua provável aparência, bem como as idealizações de seus retratos; 2) o contexto histórico em que viveu e as disputas políticas em que se envolveu; 3) suas relações com o mundo grego; 4) suas relações pessoais e, por fim, 5) as narrativas sobre sua vida.

De fato, ao propormos a presente reflexão, estamos situados no item 1, pois nosso objetivo é, partindo do Mosaico de Alexandre, considerado como cultura material, pensar sobre sua recepção no contexto romano na cidade de Pompeia. Nesse sentido, Hardwick 
(2003, p. 15) é uma referência importante, pois, para explorar alguns dos mecanismos de recepção na própria Antiguidade, analisaremos algumas formas de transmissão da imagem de Alexandre e as mudanças culturais para a criação de novas narrativas. Além de Hardwick, Tanner (2000, p. 18) também aponta questões relevantes, em especial ao considerar que cada vez mais é preciso ir além das interpretações formalistas das obras de arte e adotar perspectivas que permitam uma análise do contexto cultural, político e histórico mais amplo. Argumentamos, então, que ao recolocar o Mosaico de Alexandre na Casa do Fauno, de onde foi tirado no século XIX, podemos explorar outras dimensões não só dos símbolos de poder, na figura do guerreiro macedônico, mas também nas relações espaciais e culturais que se desenvolvem na casa em uma cidade romana mais periférica. Ou seja, nos propomos explorar os significados possíveis da arte e da linguagem visual em seu contexto material e histórico.

Assim, o que se segue é um estudo de caso mais aprofundado, o mosaico de Alexandre na cidade de Pompeia, para pensar as formas de recepção de Alexandre no passado, o impacto da redescoberta do Mosaico no século XIX, momento em que as disciplinas acadêmicas se formavam, e nos dias atuais. Para tanto dividimos o artigo da seguinte forma: iniciamos problematizando aspectos da escavação da cidade de Pompeia para, na sequência, discutirmos a Casa do Fauno e descrever os detalhes do Mosaico. Após essas questões iniciais, analisamos os primeiros estudos do Mosaico e as formas de entender a arte no século XIX para, por fim, pensar algumas das abordagens mais recentes, analisando os desdobramentos dos questionamentos pós-coloniais nas novas leituras sobre os encontros entre Oriente e Ocidente. Almejamos, com esse exercício, trazer à tona as complexas relações entre passado e presente, entre arte e materialidade, recepção e diversidade étnica.

\section{Escavando Pompeia}

Pompeia não é muito expressiva no contexto da história romana. Como Cooley \& Cooley (2004, p. 1) já destacaram, não há nenhum político ou escritor pompeiano conhecido ou nenhum fato marcante que lá ocorreu. Mas, por um acaso, Pompeia está entre as cidades romanas mais conhecidas pelas pessoas ou estudadas nas universidades ao redor do mundo. Ao ter sido soterrada por uma explosão do vulcão Vesúvio em 79 da nossa era e escavada sistematicamente a partir do século XVIII, se tornou referência sobre a arte e cultura material do mundo romano na Modernidade e segue em posição de destaque até os dias de hoje.

Essa particularidade levou muitos estudiosos a afirmarem que Pompeia seria uma espécie de cápsula do tempo, ideia essa que, nas últimas décadas, arqueólogos têm refutado. Os questionamentos se deram porque, ao longo do processo de escavação, tornou-se evidente que havia muitas perdas de material provocadas tanto pela natureza, como pela ação humana. Em primeiro lugar, o terremoto, seguido pela explosão do vulcão cerca de uma década depois, gerou muita destruição, embora a cidade tenha sido, em parte, bem preservada. Em segundo, Pompeia possui uma história muito particular de escavação, pois a atuação das pessoas na área, recuperando objetos, é anterior à própria Arqueologia como ciência e nem sempre o que foi retirado foi feito de maneira ordenada ou visando conhecer melhor o passado antigo. 
Pompeia permaneceu desaparecida até o século XVIII, quando as primeiras incursões foram feitas no local e, somente em 1763, foi confirmado que as ruínas ali presentes eram da cidade devido a uma inscrição (Funari, 2003). Nesse primeiro momento, as escavações foram feitas de forma aleatória, procurando preservar aquilo que a nobreza napolitana acreditava ser mais valioso. Neste contexto, muito se perdeu, em especial pelos constantes saques, já que no século XVIII a Arqueologia, como disciplina científica, ainda não existia, e a retirada de objetos de valor artístico de sítios abandonados ou o hábito de colecionar antiguidades era uma prática comum (Varone, 1998).

Embora durante este período algumas pessoas tenham defendido o fim das pilhagens, Etienne (1994) afirma que, somente no século XIX, a cidade passa a ter uma intervenção mais sistemática e menos destruidora. Mesmo que em alguns momentos o interesse tenha sido menor pela sua escavação, quando Fiorelli se torna responsável pelo estudo de Pompeia, muda-se o panorama, pois é com ele que a cidade passa a ter escavações mais metódicas e científicas. Foi Fiorelli, por exemplo, quem dividiu a cidade em regiões e quarteirões (insulae), sistema de demarcação utilizado até hoje pelos arqueólogos, além de ter escavado muitas regiões da cidade de maneira mais científica.

Se Fiorelli, por um lado, é um dos mais importantes arqueólogos do século XIX que atuaram em Pompeia, definindo e organizando metodologias para a escavação do sítio, Amedeo Maiuri, por outro, é o superintendente mais polêmico do século XX. Maiuri ocupou o cargo entre 1924 e 1961, desenvolvendo seus trabalhos, em parte, financiado pelo governo fascista de Mussolini. É fato que boa parte de Pompeia foi escavada neste período, no entanto, estudiosos criticam as restaurações propostas que mais indicavam uma percepção fascista do que era o Império do que uma estética romana propriamente dita. Além disso, como Cavicchioli (2004) já ressaltou, durante direção de Maiuri, muitos objetos foram retirados de seus contextos originais, em especial os que feriam a conduta de moralidade, como as pinturas e objetos com representações sexuais ou fálicas, descritas na época como pornográficas. Decisões como estas restringiam o acesso ao material escavado em Pompeia, bem como alteraram os contextos nas quais foram encontrados.

Estas considerações acerca do soterramento e posterior escavação do sítio, mesmo que tenham sido apresentadas de maneira sucinta, permitem uma reflexão particular: o que hoje consideramos o sítio arqueológico de Pompeia é um local que passou por diversas intervenções sejam elas naturais ou humanas. O terremoto e a erupção causaram destruição, já as escavações foram permeadas por saques, atravessadas pela estética napolitana, pelas primeiras escavações científicas, pelo fascismo de Mussolini e pela destruição dos bombardeios durante a II Guerra, só para citar alguns acontecimentos ao longo dos séculos. Assim, compartilhamos da perspectiva de análise que aponta que o que hoje se preservou não deve ser entendido como um exemplo direto do cotidiano de uma cidade administrada pelos romanos, mas um sítio arqueológico com uma história posterior específica. Neste sentido, ao analisarmos qualquer aspecto da cidade, não devemos tomar como um reflexo direto do passado romano, mas entendê-la como um local atravessado por tensões, disputas e conflitos, tanto no passado antigo, como em sua recuperação na Modernidade. 
A partir do exposto, ressaltamos que a aproximação que propomos de Pompeia está pautada em um viés que considera as intervenções no sítio e seus limites, visando a uma interpretação da cultura material a partir de suas particularidades, pois como afirma van Dommelen (1997), a Arqueologia permite o estudo de caso redefinindo a situação do local em que os artefatos foram encontrados. Dentro da cidade de Pompeia, nessa ocasião, portanto, focaremos na escavação da Casa do Fauno, local onde foi encontrado o Mosaico de Alexandre (atualmente sob guarda do Museu Arqueológico Nacional de Nápoles), para discutir recepção da arte helenística no passado romano, bem como os sentidos atribuídos a Alexandre nos processos de escavação do local. Trata-se de uma proposta de análise que visa a reconhecer a historicidade dos processos de escavação e interpretação, bem como os diálogos possíveis entre passado e presente. $\mathrm{Na}$ sequência, apresentamos a escavação da Casa do Fauno, a descrição do mosaico para, por fim, discutir as diferentes abordagens propostas e suas implicações políticas.

\section{a Casa do Fauno}

Fiorelli, como já comentamos, foi muito ativo na organização das escavações em Pompeia na segunda metade do século XIX, em especial na criação de vários métodos científicos para facilitar o trabalho de campo, evitar a destruição de materiais e preservar o que estava sendo encontrado. Entre tantos papéis que desempenhou como arqueólogo, cabe destacar sua preocupação como editor de publicações, algo ousado para a época. Entre 1860-1864, por exemplo, publicou os três volumes Pompeianarum Antiquitatum Historia (PAH), obra que congrega os relatos de escavação da cidade de Pompeia e suas casas a partir de 1748. Dessa experiência surgiu, em 1876, Notizie degli scavi di antichità, revista que existe até hoje e que traz informações sobre os trabalhos realizados. Essa preocupação em sistematizar e apresentar o trabalho foi fundamental para definir, pela primeira vez, uma política de publicação de boletins e relatos arqueológicos das escavações na região.

Graças a essas iniciativas, hoje podemos ter acesso a informações para entendermos as escolhas feitas pelos arqueólogos e termos acesso aos registros de como se encontrava o local no momento da escavação, algo que nem sempre conseguimos acessar em outros contextos de escavação. E é exatamente a partir da Pompeianarum Antiquitatum Historia que podemos nos aproximar dos relatos mais antigos sobre a Casa do Fauno, bem como verificar o estado em que se encontrava o mosaico de Alexandre no momento de sua descoberta. Inclusive saber que esse nome, "Casa do Fauno", é o que passou a ser oficial para designar o local, pois, como ressaltaram Cooley \& Cooley (2004, p. 211), até o advento dos métodos de escavação de Fiorelli e suas publicações, não havia um sistema único para identificar e descrever uma casa em Pompeia. Isso significa que as casas da cidade eram nomeadas aleatoriamente a partir de algum traço distintivo e esse nome poderia variar ao longo do tempo. O que hoje conhecemos como Casa do Fauno já foi chamada na literatura, por exemplo, de Casa de Pã, Casa de Goethe, Casa do Grande Mosaico, Casa da Batalha de Alexandre, entre vários outros nomes. 
Pelos relatos de escavação presentes na Pompeianarum Antiquitatum Historia sabemos que o que intrigava os responsáveis pelo trabalho na casa era a diversidade de mosaicos coloridos encontrados em seu interior. Como nesse período há uma preferência por escavar casas ricamente decoradas, a Casa do Fauno foi descrita com grandiosidade, expressões como "uma casa magnífica", "elegantemente decorada", "não há paralelos em Pompeia", dão o tom do tipo de descrição que se propunha, na época, objetiva. ${ }^{2}$ Ao que tudo indica, as escavações na casa começaram entre 1829/1830, depois que a rua já estava limpa. A entrada é descrita como surpreendente, com grande portão de madeira, decorado com fechaduras de ferro e anéis de bronze, as paredes pintadas, com quatro pequenas colunas coríntias dando vista ao interior da casa e seu átrio. No átrio, a descrição da palheta de cores, em especial a do primeiro mosaico de flores e frutos que, junto com a descrição de todo o mármore, e a pequena fonte com o deus Pã (Fauno) de bronze, demonstra como tais relatos são profundamente marcados pelos detalhes, cores e indica a construção de um discurso sobre arte e elegância. Predomina, portanto, a descrição da qualidade e do valor da arte, não necessariamente todas as etapas de sua escavação da casa. O fascínio com os mosaicos é tanto que, em dezembro de 1830, já se tem uma boa ideia de sua quantidade, levando a concluir que o dono da casa tinha um gosto único pelo luxo e riqueza, e somente o átrio poderia fornecer ao Museu Real uma riqueza sem paralelos.

Pelas descrições da casa não temos como saber quem foram seus donos, mas é possível inferir, pelo contexto arqueológico, que parte de sua estrutura e decoração foi renovada em época de presença romana, sem deixar de considerar a presença do gosto helenístico na sua decoração e a presença samnita na cidade. Nesse sentido, entendemos que a casa e sua decoração se encontram em um contexto cultural multifacetado, atravessado de, ao menos, três elementos culturais mais evidentes: romanos, helenísticos e samnita. Hoje, considera-se, portanto, como uma casa atravessada por diferentes valores culturais, que tem proporções não usuais, não seguindo as descrições vitruvianas e contendo dois átrios (Mureddu, 2015). Ao chamarmos atenção para esse ponto, levamos em conta os recentes debates sobre cultura e sociedade, destacando a complexidade cultural em que se constitui a cidade de Pompeia, e como é possível relacionar a estrutura romana da cidade com a experiência de vida cotidiana multiétnica (Laurence, 1997), tema que retomaremos mais adiante. Por hora gostaríamos de focar nossa atenção no mosaico em si.

O mosaico foi encontrado em 1831, na parte mais interna da casa, uma exedra e, dada a sua singularidade, desde então vem sendo lido e relido pelos estudiosos. Há muitos estudos e propostas de análise desde sua descoberta, mas é possível dividi-los em dois grandes grupos: há os estudiosos que propuseram lê-lo como obra única e singular dentro da casa; há os que, mais recentemente, defendem que é preciso uma análise do mosaico no contexto, isto é, em relação aos demais elementos decorativos e arquitetônicos da casa (Mureddu, 2015).

\footnotetext{
${ }^{2}$ Para extrato completo e traduzido para o inglês, cf. Cooley; Cooley (2004, p. 211).
} 
Atualmente se encontra sob guarda do Museu Arqueológico Nacional de Nápoles, e, na cidade de Pompeia, há uma réplica no local em que foi encontrado. No catálogo da instituição encontramos a seguinte descrição:

Esse mosaico de larga escala $(5.82 \times 3.13 \mathrm{~m})$ é uma das mais famosas obras de arte que chegaram até nós da Antiguidade. Foi encontrado em 24 de outubro de 1831, na casa do Fauno em Pompeia, onde decorava uma exedra retangular com colunas ao lado do peristilo central da casa. A cena narrada é uma das batalhas entre Alexandre, o Grande, que aparece de cabeça descoberta da esquerda para direita, e Dario III (em sua biga, à direita). Esse mosaico é uma cópia precisa de uma das maiores pinturas do período do início do helenismo (segunda metade do século IV antes da era comum). Há um grande debate sobre a identificação da pintura original, se foi um painel pintado por Filóxeno de Erétria para o rei Cassandro no palácio real madedônico em Pela; ou se é a obra de uma pintora egípcia Helena, filha de Timon, sobre a batalha de Issos. A largura da composição não tem precedentes, com massiva presença de homens e cavalos em frenético movimento, iluminado pela justaposição de lanças contra a luz do céu. A pintura deve ter sido muito famosa na Antiguidade, copiada em urnas funerárias etruscas e vasos de cerâmica. A técnica usada no mosaico de Pompeia é um opus vermiculatum muito sofisticado. Foi feito com cerca de um milhão de cubinhos, cada um com entre 15 e 30 centímetros quadrados. ${ }^{3}$

Essa descrição, embora sucinta e voltada para o público mais amplo, é interessante por nos apresentar uma série de elementos para discutir a recepção na arte no passado, circulação de ideias e construção da imagem de Alexandre. Inicia com sua dimensão única, apresenta sua localização em Pompeia, descreve sua grandeza e beleza com detalhes de como foi feito, em especial o tamanho dos fragmentos usados em sua composição, indica que havia outras imagens conhecidas e que circulavam no passado. De certa forma expressa aquilo que quase todos temos em mente considerando o legado de Alexandre: algo grandioso e extraordinário. Badian (1999), em um dos mais detalhados balanços sobre o que se produziu acerca do mosaico desde sua descoberta, aponta que essa percepção do mosaico como grandioso e único é carregada do romantismo de Goethe, pois, se os estudiosos do século XIX debateram os detalhes de sua composição, o escritor fez com que o mosaico se tornasse muito popular. Devido a essas particularidades, observemos, então, como foi pensado pelos arqueólogos no século XIX para, na sequência, discutirmos outras abordagens propostas mais recentemente.

\footnotetext{
${ }^{3}$ Descrição do catálogo do Museu Arqueológico Nacional de Nápoles, 2018, p. 59. Trad. Renata Senna Garraffoni.
} 


\section{O MOSAICO ONTEM}

Desde seu descobrimento, o mosaico de Alexandre foi objeto de diferentes interpretações quanto à batalha representada e seus protagonistas, bem como sobre a identidade do artista que o fez. Dentre as várias explicações, merecem ser destacadas aquelas feitas, entre 1831 e 1832, por membros do corpo científico napolitano ligados às escavações e instituições reais, como a Sociedade Real Borbônica, dividida em três academias: Academia Real de Arqueologia de Herculano, Academia Real de Ciências e Academia Real de Belas Artes, e o Museu Real Borbônico, onde, inclusive, estas academias realizavam suas sessões (cf. Galanti, 1861, p. 148).

Entre 1831 e 1832, surgiram as três principais explicações sobre a batalha representada (veja-se a imagem, no final do artigo). Considerando a composição básica do quadro, uma batalha de cavalaria, com dois grupos distintos, um à esquerda formado por guerreiros com trajes gregos e outro à direita com trajes persas, pressupôs-se tratar de uma das batalhas travadas por Alexandre, o Grande, contra Dario, o primeiro identificado no guerreiro a cavalo, com couraça e uma longa lança, com a qual está transpassando um inimigo, e o segundo, o líder persa, que está em pé na quadriga, olhando e gesticulando em direção ao cavaleiro grego. A primeira interpretação propôs ser a batalha do Granico, a segunda, a batalha de Issos, e a terceira, a batalha de Arbela; interpretações que consideram, também, a ideia de o mosaico de Pompeia ser uma cópia de um original grego, levando, por extensão, à reflexão sobre o artista que o fez.

Quanto à primeira, Pietro Bianchi (1831), arquiteto diretor das escavações em Pompeia, publicou o primeiro relato, em caráter provisório, da descoberta do mosaico, oferecendo, também, a primeira explicação da batalha representada. Considerando as vestimentas dos vencidos, bem como suas cabeças cobertas pelo característico gorro persa, conclui que os mesmos são bárbaros; enquanto o vencedor, seja pela decoração de sua couraça, pela sua atitude majestosa e belicosa e, sobretudo, por seu vulto, não é outro que o memorável Alexandre, o Grande, levando-o a entender que o quadro narra a primeira vitória de Alexandre sobre os persas nas margens do rio Granico, precisamente como narrada por Arriano, I.15.

Francesco Maria Avellino (1831), secretário da Sociedade Real Borbônica e professor da Universidade Real, de maneira independente, entendeu, do mesmo modo, ser a batalha do Granico o tema representado. Avellino oferece mais elementos para sustentar esta identificação. No reconhecimento dos persas, argumenta que, de acordo com Heródoto (V.49; VII.61), eles tinham o costume de ir à guerra com trajes típicos, como o gorro e a calça comprida. Na identificação da batalha, acrescenta que é um detalhe exclusivo da descrição de Arriano (I.15): Alexandre ferindo um oponente com a lança, no caso, Mitrídates, genro de Dario.

A segunda foi proposta por Bernardo Quaranta (1831), professor de Arqueologia e Literatura Grega da Universidade Real e sócio da Academia Real de Arqueologia de Herculano, o qual preferiu a batalha de Issos. Quaranta descreve o quadro destacando haver dois exércitos travando uma batalha, um à esquerda e outro à direita e, considerando as 
diferenças de suas vestimentas, conclui ser o primeiro grego e o segundo persa. Seguindo a história das guerras gregas com os persas, acredita que o mosaico representa a batalha de Issos; representação que traz indubitáveis indícios para reconhecer os protagonistas: Alexandre a cavalo e Dario montado no carro.

Quaranta foi o primeiro a propor que o mosaico seria uma cópia de alguma pintura famosa, feita por um pintor notório; todavia, não está totalmente convicto a quem o atribuir. Por um lado, considera que a obra oferece mais elementos para ser atribuída a Filóxeno de Erétria, o qual, de acordo com Plínio (XXV.110), pintou, a pedido do rei Cassandro, a batalha de Alexandre com Dario; por outro lado, reconhece que a pintura de Filóxeno poderia ter representado a batalha de Arbela ao invés da de Issos, defendida por ele; fato que o leva a supor, sem excluir Filóxeno, que seja, também, uma cópia de alguma pintura de Apeles, visto que o mesmo, segundo dá a entender Plínio, pode ter acompanhado Alexandre em suas expedições.

A terceira surgiu de Antonio Niccolini (1832a; 1832b), arquiteto real e presidente do Instituto Real de Belas Artes, que propôs ser a batalha de Arbela. Para chegar à sua proposição, Niccolini, primeiramente, rebate as análises de Avellino $(1831,1832)$ e de Quaranta (1831, 1832), cujos textos ele reproduz nas duas publicações de seu ensaio e faz uma análise detalhada do mosaico e dos textos dos autores antigos. Para tanto, ele confeccionou dez pranchas, contendo a visão geral do quadro e vários detalhes, e reuniu, em apêndice, os textos de Diodoro Sículo, Plutarco, Cúrcio e Arriano, conforme as três batalhas consideradas, a do Granico, de Issos e de Arbela. Considerando estes textos, Niccolini refuta a interpretação de ser a batalha do Granico com o argumento de que Dario não estava nela presente. Depois, vê na couraça de linho de Alexandre no mosaico a coincidência com a descrição de Plutarco (Alexandre, 32, 8) sobre seu uso na batalha de Arbela; fato que exclui as demais interpretações.

Estas três propostas das batalhas representadas receberam apoios com aprofundamentos dos argumentos para a sustentação de cada uma delas. A batalha do Granico foi aderida por Cataldo Jannelli (1834), a de Issos por Carlo Fea (1833), Giovanni Battista Baizin (1836; 1839) e Louis Viardot (1840), e, por fim, a de Arbela por Désiré Raoul Rochette (1833) e Antoine Chrysostôme Quatremère de Quincy (1838).

Todas estas explicações levaram em conta as versões dadas pelos autores antigos das batalhas propostas, a saber, Diodoro Sículo (Biblioteca histórica), Plutarco (Vidas), Cúrcio (História de Alexandre Magno), Arriano (Anábase de Alexandre) e Heródoto (História), bem como as informações de Plínio, o Velho (História natura), para as questões artísticas.

A batalha do Granico foi narrada por Diodoro Sículo (XVII, 19-20), Plutarco (Alexandre, 15-18), Cúrcio (III, 1, 9 e 10, 7) e Arriano (I, 12,7-16,7). A batalha de Issos por Diodoro Sículo (XVII, 34), Plutarco (Alexandre, 19-21), Cúrcio (III, 11, 1-27) e Arriano (II, 11). A batalha de Arbela por Diodoro Sículo (XVII, 55, 3-61, 3), Plutarco (Alexandre, 31-33), Cúrcio (IV, 12, 1-16, 33) e Arriano (III, 8-15). Esta última batalha ocorreu, segundo Diodoro (XVII, 61, 3) e Plutarco (Alexandre, 31, 6), não em Arbela, mas na cidade próxima de Gaugamela.

À luz destes autores, as três batalhas travaram-se no contexto da guerra de Alexandre contra Dario, ocorrida entre 334 e 331 a.C. Alexandre obteve a vitória em todas, e elas se 
deram na seguinte ordem: Alexandre conquista sua primeira vitória, em junho de 334, às margens do rio Granico, na Ásia Menor; a segunda obteve em novembro de 333, quando Dario assume pessoalmente a frente de seu exército e se defronta com Alexandre em Issos, na Síria; e, por fim, a ocorrida, em outubro de 331, a leste do alto Tigre, em Gaugamela, perto de Arbela, na Mesopotâmia (Lefèvre, 2013, p. 143-155; Straus, 2003, p. 153).

Além destas interpretações, surgiram várias que propuseram outras batalhas. Entre as quais podem ser mencionadas as seguintes: Carlo Bonucci (1832) entendeu tratar-se da batalha de Plateias; Alexandre Marchand (1833), um episódio da batalha de Maratona; Giuseppe Sanchez (1835), o confronto entre Aquiles e Heitor nas portas Esqueias em Troia; Luigi Vescovali (1832), o confronto entre gregos e celtas em Delfos; Filippo de Romanis (1833), o confronto entre Druso e os gauleses em Lyon na Gália; Pasquale Ponticelli (1834), a guerra de César contra o rei Ptolomeu de Alexandria no Egito.

Passados quinze anos do descobrimento do mosaico, Giovambatista Finati, inspetor geral do Museu Real Borbônico e sócio ordinário da Academia Real de Arqueologia de Herculano, fez um balanço sobre estas várias interpretações e concluiu que

Depois de tantas doutas conjecturas, não podemos fazer nada além de visar o seu conjunto e dizermos que está quase demonstrado que o exército vitorioso é grego e que o outro asiático é provavelmente persa [...]; e que o original desta obra portentosa pertence a um dos artistas mais famosos do século dourado da Grécia (Finati, 1846, p. 10).

Anos mais tarde, Augusto Vera, filósofo hegeliano, vai um pouco mais longe nesta direção ao concluir que a representação do mosaico vem a ser "a síntese e idealização da expedição de Alexandre, ou da luta da Grécia e da Pérsia" (Vera, 1869, col. 141). Nos dias atuais, ainda não há consenso sobre os temas que foram tratados por estes primeiros autores, mas a ferocidade da batalha nos olhares, a inteligência militar e o controle dos homens são fatores que permitem que o mosaico seja relido até na atualidade. Talvez o deslocamento maior que se tenha nas abordagens seja exatamente o que apontou Tronson (2004): com o desenvolvimento de uma arqueologia mais contextual na segunda metade do século XX, mais do que analisar a cena e contrapô-la aos textos para definir qual batalha por meio da relação texto/mosaico, os estudos se centraram em entender o mosaico não mais em si mesmo, mas no contexto da Casa do Fauno. Assim, o foco da análise passa da definição de qual foi a batalha para questões como identidade, alteridade e etnicidade, temas que abordaremos na sequência.

\section{O mosaico hoje}

Os estudos sobre o mosaico de Alexandre são, de fato, diversos ao longo dos séculos. Recentemente, Tuck (2015) afirmou que uma das razões sobre as constantes releituras de suas formas e significados é a sua policromia, pois a grande maioria dos mosaicos são em preto e branco e, por essa razão, esse aspecto em específico chama tanto a atenção. Além 
da diversidade de cores, que já foram tão descritas desde sua descoberta, atualmente muitos arqueólogos buscam entender sua presença em Pompeia, em um período anterior aos usos da imagem de Alexandre pelos imperadores romanos. Essa posição mais contextual gera outras questões sobre a relação entre culturas e extrapola a questão histórica da batalha em si, levando a reflexões sobre a produção de sua imagem de forma controlada pelo próprio líder macedônico e os desdobramentos, na posteridade, no contexto do mundo antigo.

Palagia (2015) afirma que as atitudes de Alexandre com relação a sua imagem provocaram um profundo impacto na forma de narrar seus feitos ao longo de sua vida. Sabe-se que Apeles fez muitos de seus retratos e que Alexandre tinha planos de expandir a presença de sua imagem em diferentes suportes, mas sua morte prematura fez com que seus seguidores considerassem seus planos artísticos muito extravagantes. Argumenta ainda que, ao longo de sua vida, cenas de caçada foram produzidas, assim como retratos, mas as cenas de batalhas, como a que deu origem ao mosaico de Alexandre, são posteriores a sua morte. Nessa mesma linha, Stewart (2014) afirma que batalhas, caçadas, procissões que envolvem Alexandre podem ser entendidas como alterações na arte grega: tendem à universalização da imagem do jovem líder macedônico, apontando um deslocamento da ação coletiva grega para uma individualidade de Alexandre, influenciando não só o período romano, como mais adiante o Renascimento.

Assim, mesmo que os estudiosos não sejam unânimes em definir qual exatamente seria a batalha a que a cena reporta, aspectos da narrativa presente na imagem em si têm sido bastante discutidos, em especial o embate do jovem líder macedônico contra Dario. O já citado Badian (1999, p. 78), por exemplo, apresenta uma reflexão interessante, argumentando que, se olharmos atentamente, no centro do mosaico está Dario e não Alexandre, o que o fez afirmar, em tom irônico, que o nome deveria ser Mosaico de Dario. O deslocamento criado por sua provocação insere o mosaico em um debate sobre etnicidade, indicando a necessidade de novas leituras e de uma relação mais profunda com os múltiplos significados da arte antiga, com imagens semelhantes em diferentes materiais como pinturas e vasos. Aponta, portanto, para um diálogo mais profícuo com as produções materiais e artísticas de outros povos do passado antigo; não se furta de travar um diálogo com a literatura, mas destaca a importância de conhecermos outros suportes materiais e suas narrativas de enfrentamento entre ambos os guerreiros no campo de batalha, pois na literatura Alexandre aparece mais na sua dimensão divina e não humana, como na cena do mosaico. Assim, Badian coloca em relação a cultura egípcia, babilônica, persa e grega para uma leitura mais abrangente do mosaico, destacando símbolos pouco estudados até então, como a presença da árvore morta ou a tensão das emoções na cena do mosaico.

Suas considerações nos fizeram pensar que o mosaico pode ser lido, portanto, independente da precisão de qual batalha narra, já que temos somente uma cena, como um momento bastante específico, o clímax da ação, do enfrentamento dramático entre dois líderes, ambos com feições idealizadas, mas profundamente envolta em uma atmosfera de morte. Mas a morte ou derrota de Dario pode ser entendida como dinâmica, pois, conforme Stewart (2014), se a árvore morta indica a derrota de Dario e a vitória de Alexandre, estamos 
diante de um mosaico didático que, por meio de Fortuna, ao chegar até nós, trouxe Dario vivo com ele. Um não é possível sem o outro. Assim, a batalha é a expressão da angústia, do momento do enfrentamento, por meio da simbologia da arte, dos embates entre diferentes culturas e os seus significados.

Nesse sentido, entender as prováveis razões da cena ser reproduzida em uma casa em Pompeia adquire novos significados. Ling (2005), assim como Badian (1999) e Palagia (2015), entende que o mosaico se relaciona a outras pinturas do período helenístico e chega a afirmar que é possível que tenha sido trazido para Pompeia e não feito na cidade. A casa em que se situa pertencia a pessoas da elite local que teriam condições econômicas de encomendá-lo. Assim, mesmo com as poucas informações sobre como teria chegado a Pompeia, tudo indica que o mosaico é do século II antes da era comum, quando a cidade já estava sob influência romana, embora a população samnita tivesse importante presença ainda (Mureddu, 2015). Ou seja, a questão se complexifica na medida em que a casa pode ter pertencido a diferentes elites, levando Stansbury-O’Donnell (2015, p. 345) a propor que o mosaico pode ser entendido ao menos de duas formas: se encomendado por um romano indicaria o poder de Roma, pois quando os romanos evocam Alexandre é para equiparar a sua força guerreira; se encomendado por samnita, indicaria a resistência de um reino diante de um império.

Tais leituras, cada uma a seu modo, apontam para o choque entre culturas e suas formas simbólicas de lidar com a arte e suas possíveis recepções, apontando o mosaico não como um fim em si mesmo, mas como parte da Casa do Fauno que, por si só, possui uma história própria e, como todas de Pompeia, bastante fragmentada. Talvez seja por isso que Mureddu (2015) indique a importância de entender o mosaico como dinâmico e, em sua leitura, chama a atenção para a ação, o movimento, o conflito de forças duais como vida e morte, luz e sombra, Alexandre e Dario se enfrentando. Nessa perspectiva, elementos duais da cultura egípcia, segundo o autor, estariam implícitos e conectariam o mosaico aos demais presentes na casa. O mosaico não seria apenas um exemplar da cultura helenística por si mesmo, mas os elementos da sua narrativa e o lugar em que se situa estariam em consonância com os demais elementos arquitetônicos da casa, as pinturas de parede e demais mosaicos indicando traços multiculturais de decoração ao gosto dos diferentes prováveis habitantes que a casa tenha tido. Esse tipo de leitura e deslocamento apresenta uma nova possibilidade de se entender a arte na materialidade da casa, aspecto que só pode ser explorado em sua complexidade se considerarmos os desenvolvimentos dos estudos sobre as casas de Pompeia do final da década de 1990.

Laurence (1997) afirma que, nesse momento, estudos sobre casa em Pompeia voltaram à baila, mas com uma perspectiva bastante diferente: a casa não é mais entendida somente pela sua perspectiva funcional, mas como fato social e cultural. Isso significa que a partir do final da década de 1990 os estudos passam a ter uma diversidade teóricometodológica, e o espaço não é mais visto como neutro, mas a partir dos usos dos agentes sociais e, por isso, é ativo. Nesse sentido, é preciso fazer uma distinção entre a estrutura arquitetônica e a experiência de vida em seu interior. Isso nos leva a considerar a presença 
de sujeitos que não são tradicionalmente pensados em uma casa como escravos ou mulheres, por exemplo. Uma casa, portanto, deveria ser entendida em suas tensões: seu contexto local, urbano, suas expressões de relações de gênero, da escravidão e, também, do ciclo de vida dos romanos (Laurence, 1997, p. 14).

Embora tenhamos tomado o estudo de Laurence e suas discussões sobre relações entre espaço, poder e gênero como exemplo para questionar uma percepção neutra da ocupação humana dos lugares, é preciso ressaltar que estudos mais teóricos sobre as casas em Pompeia proliferaram nesse período e, sem dúvidas, impactaram na forma de entender a presença do mosaico de Alexandre na Casa do Fauno. Zanker (1998), ao descrever a casa, o faz de maneira diferente de como era feito no século XIX, louvando a beleza dos mosaicos, e foca seus comentários nas lojas no entorno, chamando a atenção para a relações sociais em que dependentes, libertos e escravos ali trabalhavam. Assim, a Casa do Fauno teria características de uma villa (peristilos com jardins e fontes, sala com mosaicos, pequenos banhos etc.), mas com a função social urbana de período romano. Argumenta, também, que samnitas nobres construíam suas casas junto ao centro da cidade e ao comércio, já os romanos preferiam os arredores para suas villae (Zanker, 1998, p. 143). Na mesma linha, Ling (2005, p. 49-50) afirma que o mosaico é um dos indicativos da opulência da casa, mas, ao analisá-la, enfatiza sua localização entre os estabelecimentos comerciais.

Os estudos teóricos sobre espaço e contexto permitem, portanto, um olhar sobre a casa como um todo e uma série de interações: do mosaico com a casa, da casa com seu entorno e com a cidade. Essas abordagens que cruzam teorias arqueológicas e de arte, mais que buscar a descrição do evento da cena, sua precisão histórica, permitem pensar a recepção dos feitos de Alexandre em um contexto fora da possibilidade de qualquer presença histórica sua. O mosaico da Casa do Fauno indica a força da narrativa ou da memória do embate na Antiguidade, pois foi feito em outro tempo, espaço e cultura. Já suas releituras em nossa contemporaneidade permitem uma reflexão sobre o acaso de sua permanência, sobre suas imprecisões, sobre as manifestações das emoções e dramaticidade na arte antiga, seus símbolos, suas contradições políticas e culturais, sobre relações de poder e relações étnicas. O encontro da Arte com a Arqueologia, desde o século XIX, multiplicou nossas percepções sobre o mosaico, sobre a casa, sobre seus habitantes, sobre a dinâmica do espaço, daquilo que é visível e daquilo que se torna visível a partir dos debates acadêmicos e das escavações em curso.

\section{CONSIDERAÇÕES FINAIS}

Ao iniciarmos nossa reflexão com Vernant, chamamos atenção para um debate que, de certa forma, perpassa todo o artigo e é parte dos desdobramentos dos estudos arqueológicos sobre a casa. A relação entre o mosaico e os textos antigos são a base de boa parte das argumentações sobre os seus significados, mas, a partir do momento em que a Arqueologia se firma como disciplina autônoma, essa relação se altera: estudiosos passam a integrá-lo aos vasos e pinturas, destacando a relevância dos meios materiais para entender a 
cena criada séculos depois em Pompeia. Além disso, aos poucos, o seu lugar na casa passa a ser explorado e, com isso, questões como etnicidade e identidade surgem em meio às tensões provocadas pelas novas possibilidades de leitura.

O que buscamos aqui foi explorar essas tensões e transformações nos modos de ver. Foi por essa razão que optamos por contrapor os estudos do século XIX, que nos referimos aqui como "ontem", com os do final do século XX e início do XXI, nomeados nesta ocasião como "hoje". A divisão adotada não implica em ler as análises como uma evolução, mesmo porque para o entendimento global do mosaico os debates são igualmente importantes e seguem existindo até hoje. Nossa opção por essa metodologia foi para indicar como há diferenças entre perspectivas de análise, como cada época constrói suas próprias formas de entender o passado. O Alexandre do mosaico foi lido e relido por diferentes ângulos ao longo dos séculos, inclusive foi literalmente retirado da casa e levado ao Museu, exposto como uma cena única, aos moldes de quadros em uma galeria de arte, adquirindo uma presença própria nos guias do Museu Arqueológico Nacional de Nápoles, como destacamos.

Nesse sentido, uma única cena nos faz pensar sobre as variadas formas de transmissão das imagens na Antiguidade, como propôs Hardwick e, também, sua musealização mais recentemente. Passado e presente se encontram indicando que a materialidade e a arte atribuem e constroem sentidos próprios, definindo caminhos possíveis para pensarmos diversidade e etnicidade. Promovem, portanto, possibilidade de análise do contexto cultural, político e histórico.

Por essas razões, acreditamos que fazer o caminho inverso, ou seja, recolocar o Mosaico de Alexandre na Casa do Fauno, é uma estratégia para explorar outras dimensões de sua presença no passado e, também, refletir sobre as práticas arqueológicas desde o início de sua escavação. O que visamos com essa reflexão foi explorar os significados possíveis da arte em sua materialidade, bem como os significados atribuídos ao longo de sua escavação e estudos. Retomar o mosaico de Alexandre considerando todas essas perspectivas é, para nós, uma forma de explorar os múltiplos significados da materialidade da arte e sua inserção em um meio urbano dinâmico, habitado por diferentes povos e envolto de diferenças étnicas e sociais. Ressaltamos, por fim, que entendemos que o mosaico sintetiza uma cena de batalha no auge de sua dramaticidade, nos traz Alexandre e Dario até nossos dias e nos desafia a pensar sobre cultura, política e diversidade. Uma cena sempre aberta a múltiplas narrativas. 


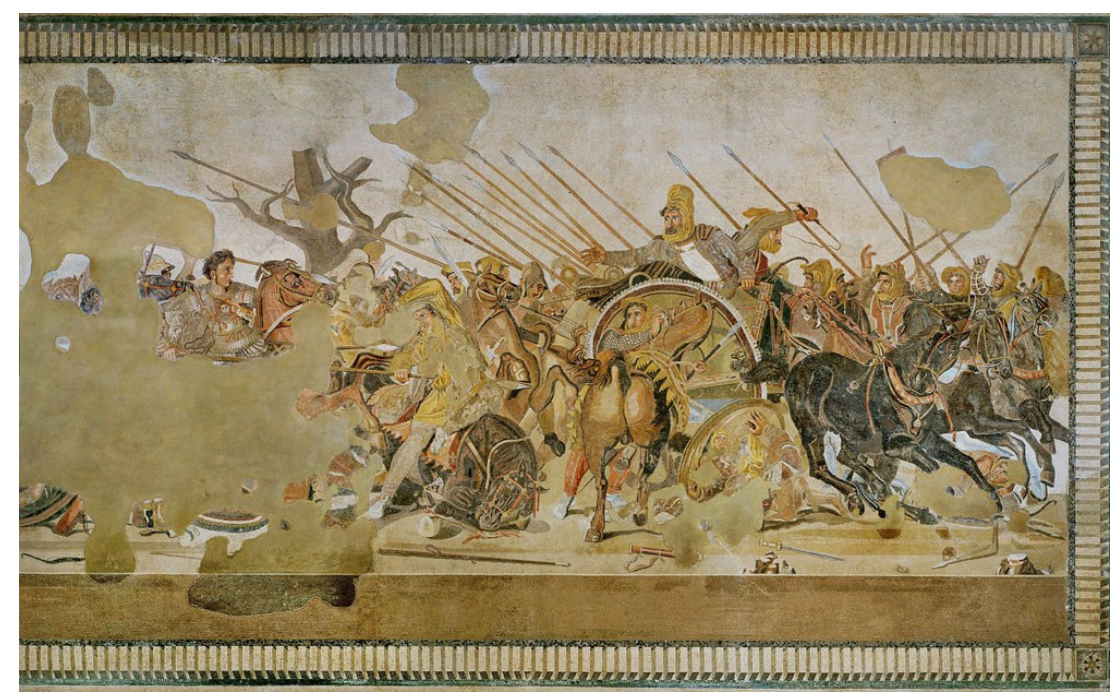

Mosaico de Alexandre

Fonte: Wikimedia Commons

https://commons.wikimedia.org/wiki/File:Alexander_(Battle_of_Issus)_Mosaic.jpg

\section{REFERÊNCIAS}

\section{Catálogos}

FIORELLI, Giuseppe. Pompeianarum Antiquitatum Historia, 1860-1864.

THE NATIONAL ARCHAEOLOGICAL MUSEUM OF NAPLES. Napoli: Electa, 2018.

\section{Autores ANTigos}

ARRIANO. Anabasi di Alessandro. Testo critico e traduzione a cura di Francesco Sisti. Milano: Fondazione Lorenzo Valla; Arnoldo Mondadori, 2004. v. 1.

CURZIO RUFO. Storie di Alessandro Magno. Testo latino e traduzione a cura di Alberto Giacone. Torino: UTET, 1977.

DIODORUS SICULUS. Library of History. With an English translation by Charles Bradford Welles. Cambridge, MA: Harvard University, 1963. v. 8. (Loeb Classical Library, 422).

ERODOTO. Le storie. Testo greco a cura di Aristide Colonna e traduzione a cura di Fiorenza Bevilacqua. Torino: UTET, 1996. v. 2.

PLÍNIO, o Velho. Naturalis Historia. Seleção e tradução de Antonio da Silveira Mendonça. Revista de História da Arte e Arqueologia, v. 2, p. 317-30, 1995-1996.

PLUTARCO, Vite. Testo greco e traduzione a cura di Domenico Magnino. Torino: UTET, 1996. v. 4. 


\section{Bibliografia MODERNA}

AVELLINO, Francesco Maria. Articolo inserito nel giornale del Regno delle due Sicilie al num. 258. In: NICCOLINI, Antonio. Musaico scoperto in Pompei il di 24 ottobre 1831. Real Museo Borbonico. Volume ottavo. Napoli: Stamperia Reale, 1832. v. 8, p. 51-4.

AVELLINO, Francesco Maria. Notizie interne. Napoli 4 novembre. Giornale del Regno delle Due Sicilie, n. 248, p. 1001-2, nov. 1831.

BADIAN, Ernest. A note on the Alexander Mosaic. In: TITCHENER, B.; MOORTON, R. F. (ed.). The eye expanded: life and the arts in Greco-Roman antiquity. Berkeley: University of California Press, p. 75-92.

BAIZINI, Giovanni Battista. Alcuni tratti dello storico Q. Curzio confrontati col gran musaico di Pompei. Roma: Tipografia Marini, 1839.

BAIZINI, Giovanni Battista. Due lettere sopra il musaico di Pompei. Bergamo: Mazzoleni, 1836.

BIANCHI, Pietro. Scavi di Pompei. Biblioteca Italiana. Giornale di Letteratura, Scienze ed Arti, n. 64, p. 132-5, ott. 1831.

BONUCCI, Charles. Grande mosaïque de Pompéi. Naples: Trani, 1833.

CAVICCHIOLI, Marina Regis. As representações da sexualidade na iconografia pompeiana. Dissertação (Mestrado em História) - Programa de Pós-Graduação em História, Universidade Estadual de Campinas, Campinas, 2004.

COOLEY, Alison; COOLEY, Melvin George Lowe. Pompeii: a sourcebook. London: Routledge, 2004.

DE ROMANIS, Filippo. Ragionamento sopra il meraviglioso mosaico rinvenuto negli scavi pompejani il di 24 ottobre 1831. Diario di Roma. Notizie del Giorno, n. 27, p. 3-4, 1833.

ETIENNE, Robert. Pompeii: The day a city died. New York: Thames and Hudson, 1994.

FEA, Carlo. Supplemento allo scritto finora da molti sul celebre musaico scoperto nelle ruine di Pompei li 24 ottobre 1831. Roma: Tipografia delle Belle Arti, 1833.

FINATI, Giovambattista. Sala del gran mosaico pompeiano. Cenno. Napoli: Tipografia Reale, 1846.

FUNARI, Pedro Paulo Abreu. A vida quotidiana na Roma Antiga. São Paulo: Annablume, 2003.

GALANTI, Luigi. Guida per Napoli e suoi contorni. 4a ed. Napoli: C. Boutteaux e M. Aubry, 1861.

HARDWICK, Lorna. Reception studies. Greece \& Rome. New Surveys in the Classics. Cambridge: Cambridge University, 2003.

JANNELLI, Cataldo. Nuove riflessioni sul gran Musaico Pompejano per dimostrarvi la battaglia di Alessandro il Macedone al Granico. Il Progresso delle Scienze, delle Lettere e delle Arti, v. 8, p. $36-51,1834$. 
LAURENCE, Ray. Space and text. In: LAURENCE, R.; WALLACE-HADRILL, Andrew. Domestic space in the Roman world: Pompeii and beyond. Road Island: Portsmouth, 1997, p. 7-14.

LEFÈVRE, François. História do mundo grego antigo. São Paulo: Martins Fontes, 2013.

LING, Roger. Pompeii: History, life and afterlife. London: Tempus, 2005.

MARCHAND, Alexandre. Mosaïques de Pompéi. Revue de Paris, v. 50, p. 110-25, 1833.

MUREDDU, Nicola. The Gorgon and the Cross. Rereading the Alexander Mosaic and the House of the Faun at Pompeii. Rosetta, v. 17, p. 52-71, 2015.

NICCOLINI, Antonio. Musaico scoperto in Pompei il di 24 ottobre 1831. In: NICCOLINI, Antonio. Musaico scoperto in Pompei il di 24 ottobre 1831. Real Museo Borbonico. Volume ottavo. Napoli: Stamperia Reale, 1832a. p. 1-87, I-XXV; pr. XXXVI-XLV.

NICCOLINI, Antonio. Quadro in musaico scoperto in Pompei a di 24 ottobre 1831. Napoli: Stamperia Reale, $1832 \mathrm{~b}$.

PALAGIA, Olga. Impact of Alexander the Great on the Arts of Greece. Leiden: The Babesh Foundation, 2015.

PANCALDI, Carlo. Le corone siciliane o il grande musaico pompejano, illustrato nel suo vero subietto. Apostrofe storico-archeologico-artistico. Napoli: Francesco Azzolino, 1845.

POLLINI, John. From republic to empire: rhetoric, religion, and power in the visual culture of ancient Rome. Norman: University of Oklahoma, 2012.

PONTICELLI, Pasquale. Illustrazione di un bel musaico pompejano. Napoli: Stamperia Real, 1834.

QUARANTA, Bernardo. Cenni. In: NICCOLINI, Antonio. Musaico scoperto in Pompei il di 24 ottobre 1831. RealMuseo Borbonico. Volume ottavo. Napoli: Stamperia Reale, 1832. p. 55-68.

QUARANTA, Bernardo. Cenni sulgran musaico disotterrato in Pompei il 24 ottobre del 1831. Napoli: Stamperia Reale, 1831.

QUATREMÈRE DE QUINCY, Antoine Chrysostôme. Dissertation sur la mosaïque dite d'Alexandre a Arbelles. In: MAZOIS, François; GAU, François C. (ed.). Les ruines de Pompée. Paris: Firmin Didot, 1838. 4e partie, p. 87-91.

ROCHET'TE, Désiré Raoul. Lettre à $M$. de Salvandy sur l'état actuel des fouilles de Pompeï et des musées de Naples et Rome. Paris: Henri Fournier, 1841.

ROCHETTE, Désiré Raoul. Quadro in musaico scoperto in Pompei, descritto dal Ant. Niccolini. Napoli 1832. Gran musaico di Pompei, descritto dal C. Bonucci. Napoli 1832. Journal des Savants, p. 286-298, 1833.

SANCHEZ, Giuseppe. Il gran musaico pompeiano. Napoli: Tipografia Trani, 1835.

STANSBURY-O'DONNELL, Mark. A bistory of Greek Art. Oxford: Wiley Blackwell, 2015. 
STEWART, Andrew. Art in the hellenistic world: an introduction. Cambridge: Cambridge University Press, 2014.

STRAUS, Barry S. Alexander: the military campaign. In: ROISMAN, Joseph (ed.). Brill's companion to Alexander the Great. Leiden: Brill, 2003, p. 133-57.

TANNER, Jeremy. Portraits, Power, and Patronage in the Late Roman Republic. Journal of Roman Studies, v. 90, p. 18-50, 2000.

TRONSON, Adrian. Resenha de "Roisman, J. (org.) Brill's Companion to Alexander the Great". The Classical Review, v. 54, n. 2, p. 460-72, 2004.

TUCK, Steven. A History of Roman Art. Oxford: Wiley Blackwell, 2015.

VAN DOMMELEN, Peter. Colonial constructs: colonialism and Archaeology in the Mediterranean. World Archaeology, v. 28, n. 3, p. 305-23, 1997.

VARONE, Antonio. Gli scavi dal 1748 al 1815. In: D’AMBROSIO, A. (org.). Alla scoperta di Pompei. Milano: Electra, 1998, p. 7-17; 59-60.

VERA, Augusto. Nuova dichiarazione del Gran Musaico Pompeiano. Giornale degli Scavi di Pompei, v. 6, col. 139-141, 1869.

VERNANT, Jean-Pierre. Préface. In: La cité des images: religion et société en Grèce antique. Lausanne: Fernand Nathan; Paris: L.E.P., 1984, p. 4-5.

VESCOVALLI, Luigi. Discorso sul gran musaico pompeiano. Roma: Tipografia Salviucci, 1832.

VIARDOT, Louis. Pompeï. Revue des Deux Mondes, v. 23, p. 622-38, 1840.

ZANKER, Paul. The power of images in the Age of Augustus. Ann Arbor: University of Michigan, 1988. 